\title{
ANÁLISE DO CICLO DE VIDA DE CONCRETOS CONTENDO AREIA RECICLADA DE CONCRETO
}

\author{
BELISÁRIO, ELISA \\ Engenheira civil \\ Universidade Federal do Rio de Janeiro \\ Rio de Janeiro; Brasil \\ elisa.belisario@gmail.com
}

\author{
TOLEDO FILHO, ROMILDO \\ Engenheiro Civil \\ PEC/COPPE/UFRJ \\ Rio de Janeiro; Brasil \\ rdtoledofilho@gmail.com
}

\section{RESUMO}

A indústria da construção civil é responsável por grandes impactos ao meio ambiente, desde a extração de matérias primas até o descarte final dos materiais. A extração dos agregados gera impactos geológicos e visuais, enquanto a disposição inadequada de resíduos de construção e demolição podem acarretar problemas estéticos, ambientais e de saúde pública, como proliferação de vetores, entupimento de estruturas de drenagem e inviabiliza a utilização de grandes espaços. A conscientização sobre a proteção ambiental faz com que alternativas venham sendo desenvolvidas para minimizar os impactos ambientais da produção do concreto, como por exemplo a reutilização de resíduos de construção. Este trabalho utilizou a metodologia da avaliação do ciclo de vida (ACV) para avaliar o desempenho ambiental de concretos de classe de resistência de $30 \mathrm{MPa}$ e $60 \mathrm{MPa}$ com diferentes frações de substituição de agregados miúdos naturais por agregados miúdos provenientes da reciclagem de resíduos de concreto. O potencial de geração de impactos levou em consideração a resistência mecânica e a durabilidade frente ao ambiente ao qual a estrutura estará exposta ao longo de sua vida útil. Os resultados mostram que a utilização do agregado reciclado é viável desde que utilizados em frações de $25 \%$ em concretos com classe de resistência convencional, no entanto devem ser observadas as características do concreto de origem do resíduo, uma vez que estes influenciaram de forma significativa a durabilidade das estruturas.

Palavras-chave: ACV, RCD, agregado reciclado, concreto.

\section{ABSTRACT}

The construction industry is responsible for many environmental impacts, from raw material extraction to final material disposal. Aggregate extraction generates geological and visual impacts, while improper disposal of construction and demolition waste can cause aesthetic, environmental and public health problems such as proliferation of vectors, clogged drainage structures and unviability of large spaces. Awareness about environmental protection results in the development of alternatives to minimize the environmental impacts of concrete production, such as the reuse of construction waste. This work used the Life Cycle Assessment (LCA) methodology to evaluate the environmental performance of concretes with $30 \mathrm{MPa}$ and $60 \mathrm{MPa}$, with different fractions of natural sand replacement by recycled sand of concrete waste. The potential impact has taken into account the mechanical strength and durability of the structure. The results show that the use of recycled aggregate is feasible as long as it is used in $25 \%$ fractions in concretes with conventional strength class. However, the characteristics of the original concrete of the waste must be observed, as they have a significantly influenced in the durability of the structures.

Keywords: $L C A, C D W$, recycled aggregate, concrete.

\section{INTRODUÇÃO}

A construção civil possui um papel importante no desenvolvimento da economia de um país, contribuindo para a geração de emprego e renda. Através dela é produzida infraestrutura econômica por meio da instalação de portos, ferrovias, rodovias, sistemas de irrigação, energia, dentre outros, facilitando o desenvolvimento de outras atividades econômicas (TEIXEIRA \& DE CARVALHO, 2005). 
No entanto, as atividades de construção e demolição são responsáveis pela geração de milhões de toneladas de resíduos, os quais impactam o meio ambiente quando descartados de maneira inadequada. Estima-se que no Brasil tenham sido produzidos 41,5 milhões de toneladas de resíduos na construção civil durante o ano de 2016 (ABRELPE, 2017).

A disposição final destes materiais requer áreas muito grandes e específicas para este tipo de resíduo, o que é considerado raro nas proximidades dos centros urbanos onde os mesmos são gerados. Tal fato aumenta a chance de deposição em locais inapropriados, podendo causar interferências no trânsito e na circulação de pedestres. Além disso, existe ainda a possibilidade de obstrução dos dispositivos de drenagem, contribuindo para eventos de inundação.

A compreensão quanto à consequência destes impactos ao meio ambiente e ao homem trazem à tona a preocupação com o desenvolvimento sustentável que deve estar incorporado às atividades da engenharia civil, possibilitando o crescimento e desenvolvimento econômico com um baixo impacto ambiental.

Nesse sentido, o beneficiamento desses resíduos para posterior utilização como agregados reciclados surge como alternativa tanto na prevenção de impactos relacionados a disposição final do resíduo de construção e demolição (RCD) em aterros ou outra destinação, quanto na de extração de recursos naturais.

A análise e comparação dessa e de outras alternativas potencialmente ecológicas pode ser realizada a partir de ferramentas de gestão ambiental como a análise do ciclo de vida (ACV). A partir desta metodologia é possível extrair indicadores ambientais objetivos com a compilação de entradas, saídas e impactos ambientais potenciais de um sistema de produto ao longo do seu ciclo de vida.

Dessa forma, esse trabalho visa utilizar esta ferramenta para comparar o desempenho ambiental de concretos convencionais e concretos moldados com diferentes teores de substituição de agregado miúdo natural por agregado miúdo reciclado. O potencial de impacto das misturas foi calculado levando-se em consideração as características de resistência mecânica e durabilidade. Foram contabilizados os impactos evitados com a não destinação dos RCD à aterros inertes quando da sua utilização como agregados reciclados.

\section{METODOLOGIA}

Para se alcançar o objetivo proposto e apresentado neste trabalho foi utilizada a metodologia da Avaliação do Ciclo de Vida (ACV), conforme estabelecido nas normas ABNT ISO 14.040 e 14.044, a qual está dividida em quatro etapas: (i) definição de objetivo e escopo; (ii) análise de inventário; (iii) avaliação de impacto e (iv) interpretação. Para isso o processo de confecção dos concretos, incluindo o beneficiamento do RCD em agregado reciclado, assim como a destinação final dos resíduos, foi modela no software SimaPro, a partir do banco de dados disponível no Ecoinvent.

A Figura 1 ilustra a fronteira do sistema considerado. Como pode ser observado a modelagem proposta considerou os impactos gerados na obtenção da matéria-prima virgem e processamento dos agregados naturais, superplastificante e cimento e o seu transporte até a central de concretagem. Para os agregados reciclados, não foram consideradas as atividades de demolição da estrutura existente. Os impactos foram contabilizados a partir do transporte do RCD até a usina de beneficiamento e, posteriormente até a central de concretagem. A linha tracejada indica o processo evitado com a utilização do RCD como agregado reciclado.

Dentre as metodologias de avaliação de impacto disponíveis no software Simapro foi utilizada a CML-IA, baseada numa abordagem "midpoint". Foram analisados os potenciais de impacto para 6 categorias, a saber:

- Depleção de recursos abióticos (ADP-ff): Categoria mensurada em MJ/kg de material. Está relacionada à extração de combustíveis fósseis em razão do consumo de matérias-primas no sistema de produto;

- Mudanças climáticas (GWP100): impacto referente às emissões de gases de efeito estufa em um horizonte de 100 anos. Esta categoria de mpacto é mensurada em $\mathrm{kg}$ de dióxido de carbono $\left(\mathrm{CO}_{2}\right)$ equivalente/ $\mathrm{kg}$ de emissões.

- Depleção do ozônio estratosférico (ODP): mensura as emissões de diferentes gases que contribuem para o aumento da depleção da camada de ozônio, e que, consequentemente, permitem uma maior radiação UV-B. Esta categoria tem como unidade $\mathrm{kg}$ de clorofluorcarbono (CFC-11) equivalente/ $\mathrm{kg}$ de emissões.

- Acidificação (AP): mensura o potencial de acidificação para emissões à atmosfera em kg de dióxido de enxofre $\left(\mathrm{SO}_{2}\right)$ equivalente/ $\mathrm{kg}$ de emissões. 
- $\quad$ Eutrofização (EP): inclui todos os impactos devidos a níveis excessivos de nutrientes no ambiente causados pela emissão para o ar, a água e o solo. Esta categoria é expressa em $\mathrm{kg}$ de $\mathrm{PO}_{4}{ }^{-3}$ equivalente/kg de emissões.

- $\quad$ Formação de foto-oxidantes (POCP): consiste na formação de ozônio troposférico, substâncias reativas, prejudiciais à saúde humana, aos ecossistemas e à agricultura. Esta categoria é expressa em $\mathrm{kg}$ de etileno $\left(\mathrm{C}_{2} \mathrm{H}_{4}\right)$ equivalente/kg de emissões.

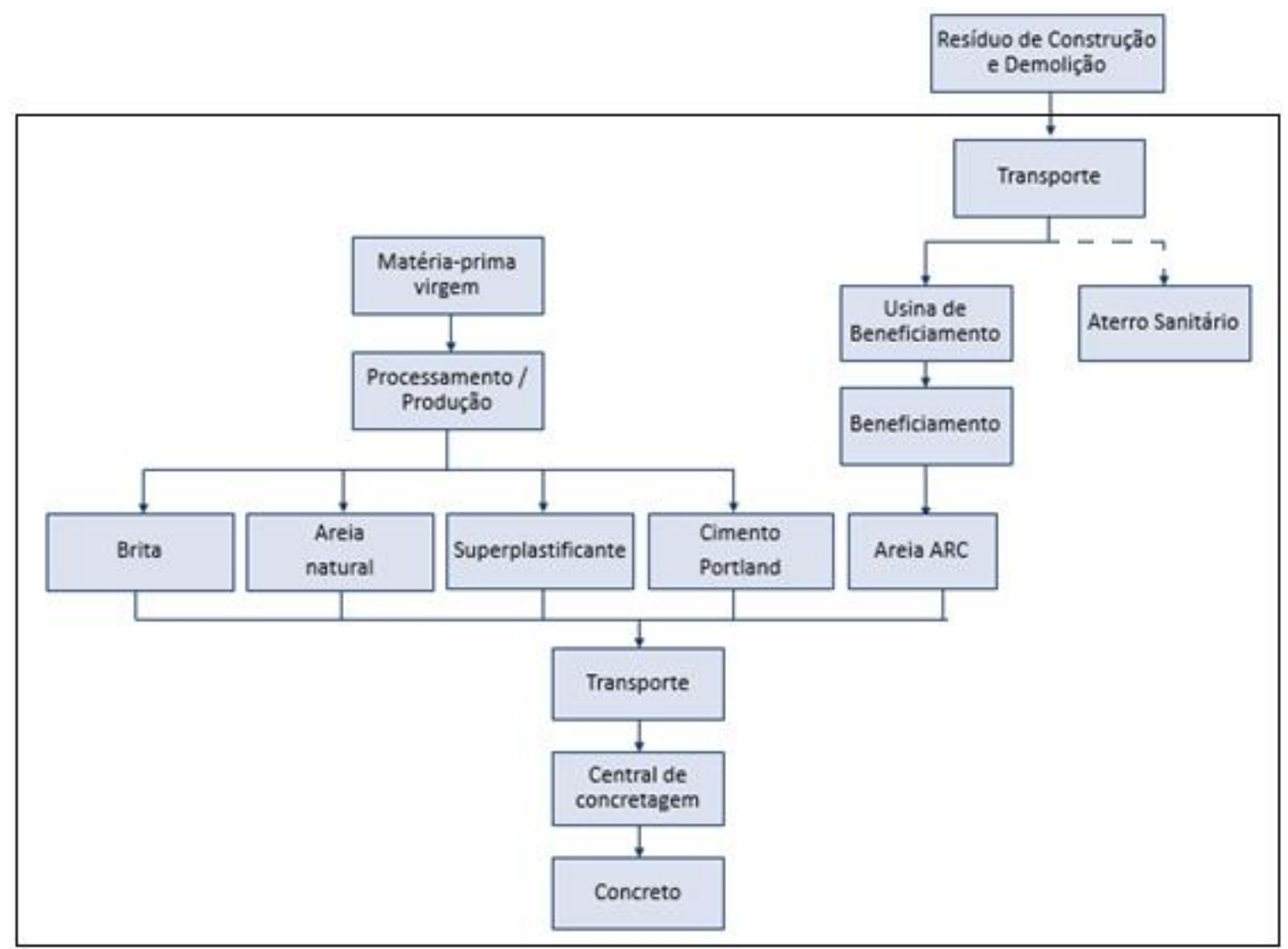

Figura 1: Fronteira considerada para modelagem dos processos no programa SimaPro

\subsection{Descrição dos concretos avaliados}

Os concretos avaliados foram originalmente objeto de pesquisa de Andrade (2018). A autora considerou duas classes de resistência C30 e C60, ambas com substituição de areia natural por areia reciclada em teores de $0,25 \%$ e $50 \%$.

Foram utilizados agregados reciclados provenientes tanto de um processo de beneficiamento feito em laboratório (Areia $\mathrm{LAB}$ ), quanto de uma usina de reciclagem de resíduos externa (Areia D).

A Tabela 1 apresenta a dosagem de cada mistura e indica o percentual de agregado reciclado de concreto (ARC), assim como a sua origem.

\subsubsection{Desempenho mecânico}

A resistência à compressão após 28 dias de cura das misturas estudadas segue apresentado na Tabela 2 a seguir. Percebe-se que, de maneira geral, a utilização dos agregados reciclados não teve impacto negativo no desempenho mecânico das misturas, sendo, em alguns casos, ligeiramente superior aquele obtido pelo concreto de referência. Com relação ao teor de substituição, percebe-se que a resistência mecânica das misturas com $25 \%$ de areia reciclada foi superior à dos concretos com $50 \%$ de areia reciclada. 
Tabela 1: Dosagem das misturas estudadas

\begin{tabular}{c|c|c|c|c|c|c|c}
\hline Misturas & $\begin{array}{c}\text { Cimento } \\
\text { Portland } \\
\left(\mathrm{kg} / \mathrm{m}^{3}\right)\end{array}$ & $\begin{array}{c}\text { Areia } \\
\text { Natural } \\
\left(\mathrm{kg} / \mathrm{m}^{3}\right)\end{array}$ & $\begin{array}{c}\text { Areia } \\
\text { RCD } \\
\left(\mathrm{kg} / \mathrm{m}^{3}\right)\end{array}$ & $\begin{array}{c}\text { Brita 0 } \\
\left(\mathrm{kg} / \mathrm{m}^{3}\right)\end{array}$ & $\begin{array}{c}\text { Água } \\
\left(\mathrm{kg} / \mathrm{m}^{3}\right)\end{array}$ & $\begin{array}{c}\mathrm{SP} \\
\left(\mathrm{kg} / \mathrm{m}^{3}\right)\end{array}$ & Descrição \\
\hline REF 30 & 329,3 & 906,8 & 0,0 & 843,5 & 219,1 & 1,25 & Concreto de referência Classe C30 \\
\hline LAB C30-25 & 324,5 & 696,4 & 197,3 & 842,1 & 223,3 & 1,24 & Classe C30 com 25\% de areia LAB \\
\hline D C30-25 & 318,5 & 705,8 & 201,1 & 853,5 & 220,6 & 1,21 & Classe C30 com 25\% de areia D \\
\hline LAB C30-50 & 312,3 & 490,2 & 396,9 & 846,9 & 223,4 & 1,19 & Classe C30 com 50\% de areia LAB \\
\hline D C30-50 & 329,6 & 488,0 & 397,2 & 843,1 & 235,6 & 1,25 & Classe C30 com 50\% de areia D \\
\hline REF C60 & 533,0 & 843,1 & 0,0 & 784,3 & 197,5 & 1,69 & Concreto de referência Classe C60 \\
\hline LAB C60-25 & 521,6 & 645,5 & 182,9 & 780,6 & 208,2 & 1,58 & Classe C60 com 25\% de areia LAB \\
\hline D C60-25 & 519,7 & 651,8 & 185,7 & 788,2 & 207,1 & 1,65 & Classe C60 com 25\% de areia D \\
\hline LAB C60-50 & 525,0 & 452,7 & 366,5 & 782,0 & 207,5 & 1,67 & Classe C60 com 50\% de areia LAB \\
\hline D C60-50 & 535,0 & 455,5 & 370,7 & 786,9 & 207,9 & 1,70 & Classe C60 com 25\% de areia D \\
\hline
\end{tabular}

\subsubsection{Durabilidade}

A durabilidade dos concretos foi estimada como o tempo necessário para que uma dada concentração de íons cloreto penetrasse até a profundidade as armaduras. Para tanto, foram utilizados (i) os resultados do ensaio de penetração acelerada de íons cloreto, realizados por Andrade (2018), conforme as instruções da ASTM C1.202, (ii) a formulação proposta por Berke e Hick (1) e (iii) a segunda lei de Fick (2) e (3).

A fórmula empírica desenvolvida por Berke e Hick permite determinar o coeficiente de difusão aparente (Dap) a partir da carga total passante $(\mathrm{Q})$ obtida no ensaio de penetração acelerada de íons cloreto.

$$
\text { Dap }=0,0103 \times 10^{-8} \times Q^{0,84}
$$

Para se chegar ao tempo de vida útil da estrutura, foi considerada a formulação desmembrada da segunda lei de Fick, onde $\mathrm{C}_{(\mathrm{x}, \mathrm{t})}$ consiste na concentração de cloretos na profundidade $\mathrm{x}$, a partir da superfície do concreto, em um dado tempo $\mathrm{t}, \mathrm{em} \%$; $\mathrm{C}_{\mathrm{s}}$ representa a concentração superficial de cloretos (admitida como constante), em \%; Co equivale à concentração inicial de cloretos na superfície do concreto, em \%; $\mathrm{C}_{\mathrm{x}}$ representa a concentração de cloretos na profundidade $\mathrm{x}, \mathrm{em} \%$; $\mathrm{x}$ representa a profundidade, em $\mathrm{cm}$; D consiste no coeficiente de difusão de cloretos, em $\mathrm{cm}^{2} / \mathrm{ano}$; $\mathrm{t}$ representa o tempo de vida útil, em anos; e erf é a função erro de Gauss.

$$
\begin{gathered}
\operatorname{erf}(\mathrm{z})=1-\left[\left(\mathrm{C}_{\mathrm{x}}-\mathrm{C}_{0}\right) /\left(\mathrm{C}_{\mathrm{s}}-\mathrm{C}_{0}\right)\right] \\
\mathrm{t}=1 / \mathrm{D} \cdot[\mathrm{x} /(2 \cdot \mathrm{z})]^{2}
\end{gathered}
$$

Primeiramente foi calculada o valor da função erro de Gauss (erf(z)), considerado que a concentração inicial de cloreto (Co) é igual a zero (GULIKERS, 2001, MEDEIROS, 2008). Para $C_{x}$ considerou-se como concentração crítica de íons cloreto o percentual de $0,4 \%$ em relação a massa de cimento (NEVILLE \& BROOKKS, 2013), MEDEIROS, 2008). O cenário de exposição considerado para a concentração de cloretos superficial $\left(\mathrm{C}_{\mathrm{s}}\right)$, corresponde a $0,9 \%$, o qual equivale a um ambiente de névoa salina (MEDEIROS, 2008).

Após definido o valor da função erro de Gauss, obteve-se "z" pela tabela da função erro. Por fim, foi aplicada em (3) para estimar o tempo de vida útil (t) de uma estrutura com um determinado cobrimento. A Tabela 2 apresenta os parâmetros de durabilidade das misturas para um ambiente de névoa salina, considerando um cobrimento de $5 \mathrm{~cm}$.

Percebe-se que quanto maior o percentual de substituição de agregado natural por agregado reciclado, menor é o tempo de vida das estruturas. Com relação à origem do resíduo, nota-se que as misturas com areia LAB obtiveram um tempo de vida maior que as misturas com areia D. Tal fato indica que o concreto de origem do resíduo LAB possui uma qualidade superior ao concreto que deu origem ao resíduo D. 
Tais informações indicam que, para um ambiente de névoa salina, os concretos confeccionados com 50\% de areia D necessitarão de uma maior quantidade de concreto, e consequentemente terão um impacto ambiental maior, para exercer a sua função estrutural.

\subsection{Definição da unidade funcional}

Atualmente, já existem alguns estudos na literatura que consideram uma análise de ciclo de vida mais abrangente, considerando a resistência mecânica da estrutura (MEDINA, 2018) e sua durabilidade (SILVA, 2015 e DE PAULA, 2016).

Buscou-se avaliar não apenas a confecção de $1 \mathrm{~m}^{3}$ de concreto, mas também o seu desempenho mecânico e sua durabilidade em um ambiente de névoa salina. Dessa forma, a unidade de referência adotada (unidade funcional) consiste no volume de concreto $\left(\mathrm{m}^{3}\right)$ necessário para desenvolver uma resistência à compressão aos 28 dias de $1 \mathrm{MPa}$ e 1 ano de vida útil.

Os fluxos de referência necessários para que cada mistura atinja a unidade funcional proposta segue na Tabela 2.

Tabela 2: Parâmetros de desempenho mecânico, durabilidade e unidade funcional dos concretos estudados

\begin{tabular}{c|c|c|c|c|c}
\hline Concreto & $\begin{array}{c}\text { Resistência à } \\
\text { compressão } \\
(\mathrm{MPa})\end{array}$ & $\begin{array}{c}\text { Carga total } \\
\text { passante }(\mathrm{C})\end{array}$ & $\mathrm{D}\left(\mathrm{cm}^{2} / \mathrm{ano}\right)$ & $\begin{array}{c}\text { Tempo de vida } \\
\text { para cobrimento } \\
\text { de 5cm }(\text { anos })\end{array}$ & $\begin{array}{c}\text { Unidade } \\
\text { funcional } \\
\left(\mathrm{m}^{3} / \mathrm{MPa} . \mathrm{ano}\right)\end{array}$ \\
\hline REF C30 & $30,40( \pm 4,76)$ & 5.142 & 4,26 & 5,02 & $6,53 \mathrm{E}-03$ \\
\hline LAB C30-25 & $31,96( \pm 3,30)$ & 6.308 & 5,05 & 4,23 & $7,40 \mathrm{E}-03$ \\
\hline D C30-25 & $32,09( \pm 6,12)$ & 6.809 & 5,39 & 3,97 & $7,85 \mathrm{E}-03$ \\
\hline LAB C30-50 & $31,48( \pm 2,62)$ & 7.128 & 5,5 & 3,82 & $8,32 \mathrm{E}-03$ \\
\hline D C30-50 & $28,07( \pm 2,51)$ & 8.344 & 6,39 & 3,34 & $1,07 \mathrm{E}-02$ \\
\hline REF C60 & $60,40( \pm 2,46)$ & 1.828 & 1,79 & 11,97 & $1,38 \mathrm{E}-03$ \\
\hline LAB C60-25 & $61,24( \pm 4,81)$ & 2.696 & 2,47 & 8,64 & $1,89 \mathrm{E}-03$ \\
\hline LAB C60-50 & $58,83( \pm 2,59)$ & 2.968 & 2,68 & 7,97 & $2,08 \mathrm{E}-03$ \\
\hline D C60-25 & $60,23( \pm 3,44)$ & 3.425 & 3,03 & 7,07 & $2,41 \mathrm{E}-03$ \\
\hline D C6-50 & $58,84( \pm 4,26)$ & 3.971 & 3,43 & 6,24 & $2,72 \mathrm{E}-03$ \\
\hline
\end{tabular}

\subsection{Inventário do ciclo de vida}

\subsubsection{Cimento}

A produção do cimento e seu transporte foram modelados no software SimaPro por meio dos processos "Cement, Portland $\{$ RoW $\} \mid$ production”, e “Transport, freight, lorry > 32 metric ton, EURO4 \{GLO $\} \mid$ market for".

Para a modelagem do transporte do material até a central de concretagem, foi considerada a distância média de $300 \mathrm{~km}$ em modal rodoviário (DNPM, 2009).

\subsubsection{Superplastificante}

Os impactos ambientais gerados durante o processo de fabricação do superplastificante tiveram como base a informação constante na Declaração Ambiental da European Federation of Concrete Admixture Associations (EFCA, 2015). Foi considerada a distância de $824 \mathrm{Km}$ entre o local de produção e a central de concretagem, feita por modal rodoviário, com caminhões de capacidade de 7,5 a 16 toneladas, movido a diesel.

\subsubsection{Brita natural}

Para a brita natural foi considerado o processo "Gravel, crushed $\{$ RoW $\} \mid$ production" disponível na base de dados do software SimaPro. O cadastro nacional de produtores de brita feita pelo DNPM para o ano de 2015, indica 6 usinas de britagem no município do Rio de Janeiro, localizadas entre as zonas oeste e norte, dessa forma, optou-se por considerar 
uma distância média de $30 \mathrm{Km}$ entre a pedreira e a central de concretagem. O veículo considerado consiste em caminhões com capacidade de 16 a 32 toneladas, movidos a diesel.

\subsubsection{Areia natural}

Para o processo de obtenção da areia natural foi considerado o processo "Sand $\{$ RoW $\} \mid$ gravel and quarry operation", existentes na base de dados do Ecoinvent. Foi considerada a distância média de $60 \mathrm{Km}$, feita por caminhões com capacidade de 16 a 32 toneladas, movidos a diesel.

\subsubsection{Agregado reciclado}

Para a modelagem do processo de beneficiamento do RCD, considerou uma usina de beneficiamento de nível 3, conforme a configuração proposta por Coelho e De Brito (2013), a qual implica em um grau de mecanização e automação capaz de separar o RCD recebido em materiais de diferentes frações, como agregados de concreto, agregados cerâmicos, ferro, material não ferroso, papel e cartão, plástico, madeira e gesso.

Segundo Coelho e De Brito (2013), o processo de beneficiamento da usina envolve, praticamente, apenas consumo de energia. Sabe-se que durante sua operação também há impactos relacionados à ruídos e geração de poeira, entretanto, estes são minimizados por regulamentos nacionais e municipais de operação das indústrias.

A Tabela 3 a seguir apresenta o consumo de energia previsto para a usina estudada por Coelho e De Brito (2013), a qual possui capacidade de processamento de 350 toneladas de RCD. Como pode ser visto, a usina consome um total de $1.309,63 \mathrm{~kW} /$ hora durante o beneficiamento, ou seja, são consumidos aproximadamente $3,74 \mathrm{~kW} / \mathrm{hora}$ para cada tonelada de RCD.

Tendo em vista que o beneficiamento dos resíduos gera diferentes frações de agregados reciclados, e a fração considerada na confecção dos concretos consiste na areia, foi considerada $43 \%$ da demanda de energia para a areia LAB e $18,9 \%$ para areia D, conforme estudo realizado por Rangel (2019).

Existem duas etapas de transporte destes agregados, sendo a primeira entre o local de geração dos resíduos até a usina de beneficiamento, e a segunda entre a usina de beneficiamento e a central de concretagem. Foi considerado que essas duas distâncias somadas correspondem a $30 \mathrm{~km}$, conforme indicado por Paula (2016).

Tabela 3 - Consumo de energia dos equipamentos da Usina de Beneficiamento proposta por Coelho e De Brito (2013)

\begin{tabular}{c|c|c|c}
\hline Equipamento & kWh/equipamento & Qtd equipam. & kWh total \\
\hline Básculas & 0,05 & 1 & 0,05 \\
\hline Escavadora & 90 & 1 & 90 \\
\hline Alimentador vibratório & 16,2 & 1 & 16,2 \\
\hline Eletroímã & 6,5 & 1 & 6,5 \\
\hline Cabine separação manual & 0,28 & 1 & 0,28 \\
\hline Britadeira & 110 & 1 & 110 \\
\hline Mesa vibratória 1 & 18,5 & 3 & 18,5 \\
\hline Separado a ar & 6,3 & 1 & 18,9 \\
\hline Gerador de corrente "Eddy" & 16,4 & 1 & 16,4 \\
\hline Mesa vibratória 2 & 22,3 & 6 & 22,3 \\
\hline Separado a ar pulsante & 127 & 7 & 762 \\
\hline Espirais & 27 & 2 & 189 \\
\hline Correias transportadoras 5 m & 5,4 & 3 & 10,8 \\
\hline Correias transportadoras 10 m & 10,8 & 1 & 32,4 \\
\hline Correias transportadoras 15 $\mathrm{m}$ & 16,3 & & 16,3 \\
\hline TOTAL & 473,03 & $1.309,63$ \\
\hline
\end{tabular}


Nos casos em que o resíduo não é destinado a uma usina de beneficiamento, foi considerado o transporte entre o seu local de geração e o aterro sanitário, o qual foi estimado em $70 \mathrm{~km}$.

\subsubsection{Impactos evitados}

A utilização dos RCD como agregados reciclados implicam na não utilização da areia natural, entretanto considera o gasto energético durante o processamento do resíduo. O saldo entre esses processos consiste nos impactos evitados, os quais foram calculados a partir dos (i) impactos gerados com o processo de beneficiamento dos resíduos e as distâncias de transporte existentes entre o local de geração e a usina, (ii) impactos evitados com a não utilização dos agregados naturais e seu transporte até a central de concretagem, e (iii) impactos evitados com a não disposição e transporte dos resíduos até o aterro sanitário.

\subsubsection{Produção do concreto}

Para o processo de produção do concreto na central de concretagem, considerou-se a demanda energética de $3,83 \mathrm{kWh} / \mathrm{m}^{3}$, conforme o inventário feito por Van den Heede e De Belie (2010).

\section{RESULTADOS}

Os resultados foram apresentados em duas etapas separadamente, sendo a primeira para a confecção de $1 \mathrm{~m}^{3}$ de cada tipo de concreto. Nesta análise não está sendo levado em consideração a influência do uso dos agregados reciclados na resistência e durabilidade do concreto final.

A segunda análise é feita para a unidade funcional proposta, qual seja a quantidade de concreto necessário para gerar $1 \mathrm{MPa}$ de resistência à compressão aos 28 dias e 1 ano de vida útil.

\subsection{Avaliação do impacto do ciclo de vida da produção de $1 \mathrm{~m}^{3}$ de concreto}

As Figura 2 e Figura 3 comparam o potencial de impacto total dos concretos de classe C30 e C60 durante o processo produtivo de $1 \mathrm{~m}^{3}$ de concreto, tendo como base as misturas de referência.

Conforme pode ser observado pelos gráficos, percebe-se que a utilização de agregados reciclados é vantajosa em todos os casos. Com relação ao teor de substituição, percebe-se que as misturas com $50 \%$ de agregado miúdo reciclado apresentam um desempenho ambiental melhor do que as misturas com $25 \%$ de substituição para ambas as classes de resistência. Essa redução do potencial de impactos é mais significativa para a classe C30.

Os impactos gerados pelos concretos com $25 \%$ de substituição de agregados naturais não apresentam muita variação com relação à origem do material, de forma que as misturas moldadas com areia LAB e areia D possuem praticamente os mesmos potenciais de impacto para todas as categorias.

Já para as misturas com $50 \%$ de substituição, percebe-se uma ligeira queda nos potenciais de impacto dos concretos moldados com areia LAB quando comparados aos moldados com areia D.

Para a categoria de impacto de depleção de recursos abióticos (ADP-ff) a utilização de 25\% de areia reciclada contribuiu com uma redução de $15 \%$ do potencial de impacto nos concretos de classe C30 e $10 \%$ para os de classe 60 . Quando utilizados $50 \%$ de areia reciclada o potencial de impacto teve uma redução de cerca de $27 \%$ nos concretos convencionais e $15 \%$ nos concretos de alta resistência.

A redução dos impactos foi mais significativa na categoria de depleção da camada de ozônio (ODP), na qual a utilização de $25 \%$ de areia reciclada reduziu em $20 \%$ o potencial de impacto na classe C30 e $15 \%$ na classe C60. Com a substituição de $40 \%$ do agregado miúdo natural, o potencial de impacto da classe C30 reduz em até $40 \%$, enquanto para classe C60 a redução é de cerca de $25 \%$ em comparação com a mistura de referência.

Com relação aos potenciais de acidificação e eutrofização, a utilização de $25 \%$ de areia reciclada reduziu em $10 \%$ os impactos dos concretos de classes convencionais e 7\% os concretos de alta resistência. Os concretos com fração de 50\% de areia reciclada apresentaram uma redução do potencial de impacto de $17 \%$ na classe convencional e $10 \%$ para classe C60. 
O potencial de mudanças climáticas foi a categoria que apresentou menor influência com a substituição dos agregados naturais pelos reciclados, tendo sido reduzido cerca de $5 \%$ em concretos de alto desempenho e de 5 a $12 \%$ em concretos convencionais. Tal fato pode ser explicado a partir das dosagens das misturas. Percebe-se através da Tabela 1 , que mesmo quando utilizado areia recicla em substituição a areia natural, não houve grandes variações na quantidade de cimento utilizada. Tendo em vista que concretos com classe de resistência maiores possuem uma maior quantidade de cimento, percebe-se que a influência da utilização de agregado reciclados possui um peso menor que nos concretos convencionais.

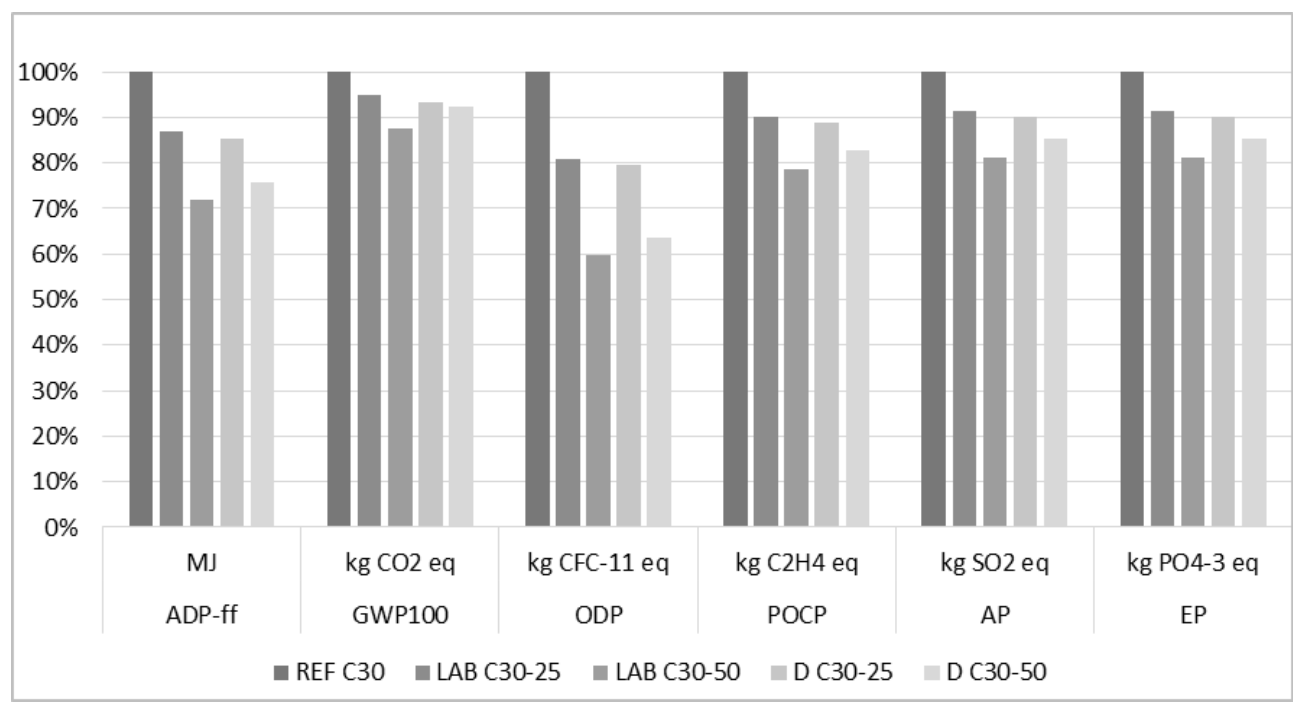

Figura 2: Análise comparativa dos impactos do ciclo de vida de $1 \mathrm{~m}^{3}$ dos concretos de classe $\mathrm{C} 30$ normalizados pelas misturas de referência

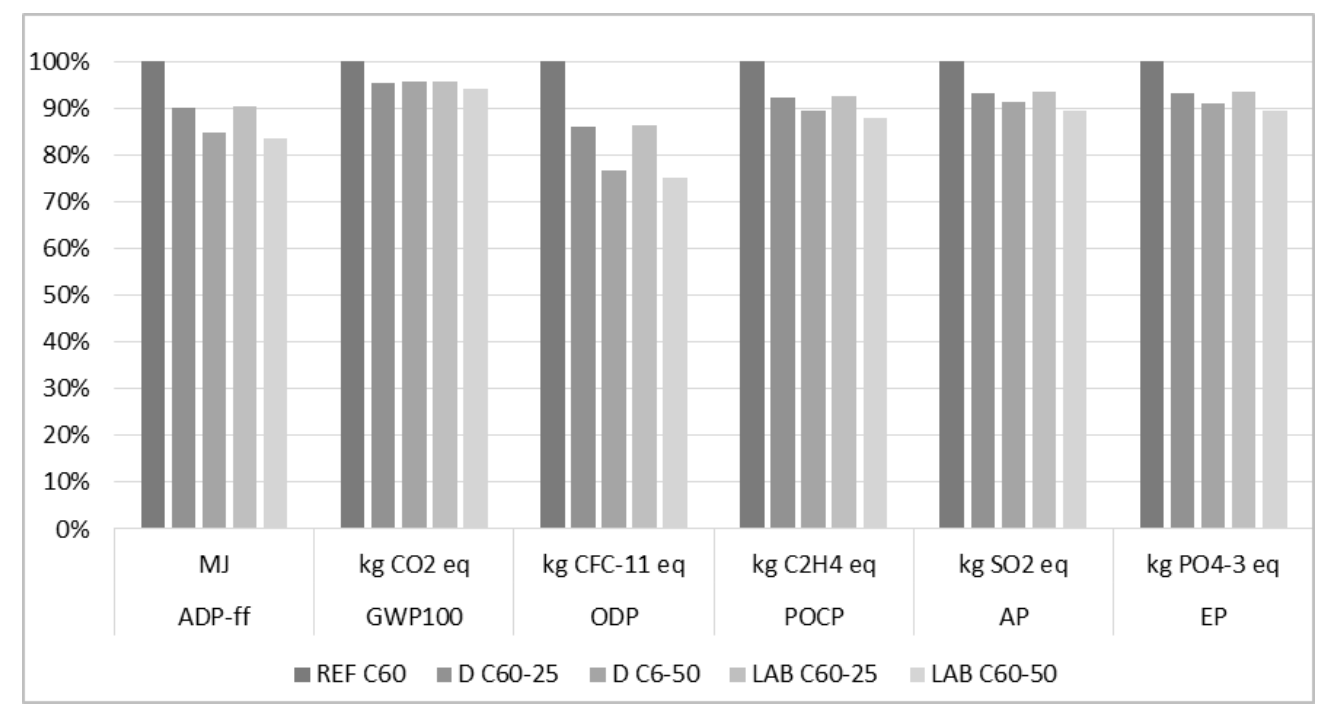

Figura 3: Análise comparativa dos impactos do ciclo de vida de $1 \mathrm{~m}^{3}$ dos concretos de classe C60 normalizados pelas misturas de referência

\subsection{Avaliação do impacto do ciclo de vida dos concretos normalizados pela unidade funcional}

As Figura 4 e Figura 5 indicam graficamente o potencial de impacto das categorias estudadas para os concretos com agregados miúdos reciclados, quando considerados conjuntamente as características de resistência mecânica e de durabilidade.

De maneira geral, percebe-se que para concretos e alta resistência, a utilização de areia reciclada, mesmo que em frações menores, não é vantajoso ambientalmente quando comparadas com a mistura de referência. A utilização da areia 
de demolição resultou em um incremento de 50 a $89 \%$ nos potenciais de impactos. Já a utilização da areia LAB resultou em incrementos que variam de 13 a $42 \%$.

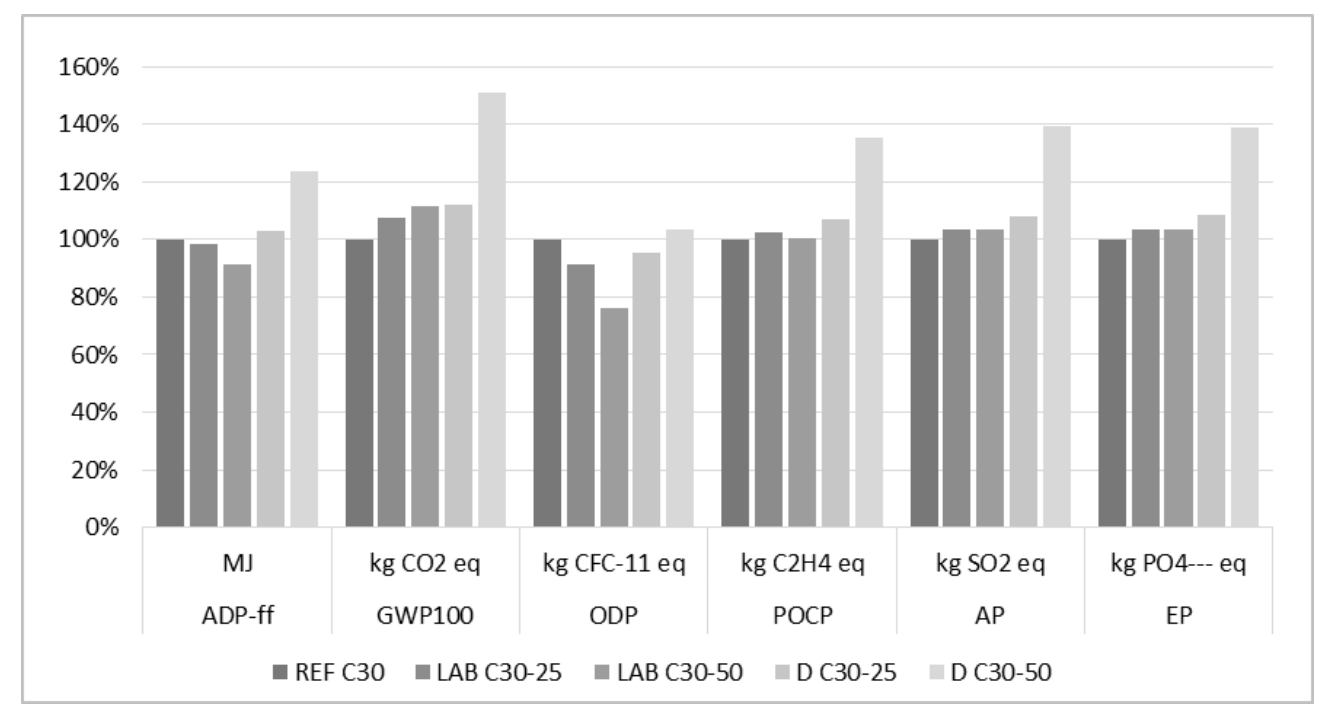

Figura 4: Potencial de impactos dos concretos C30 com 1MPa de resistência e 1 ano de vida útil, normalizados pela mistura de referência

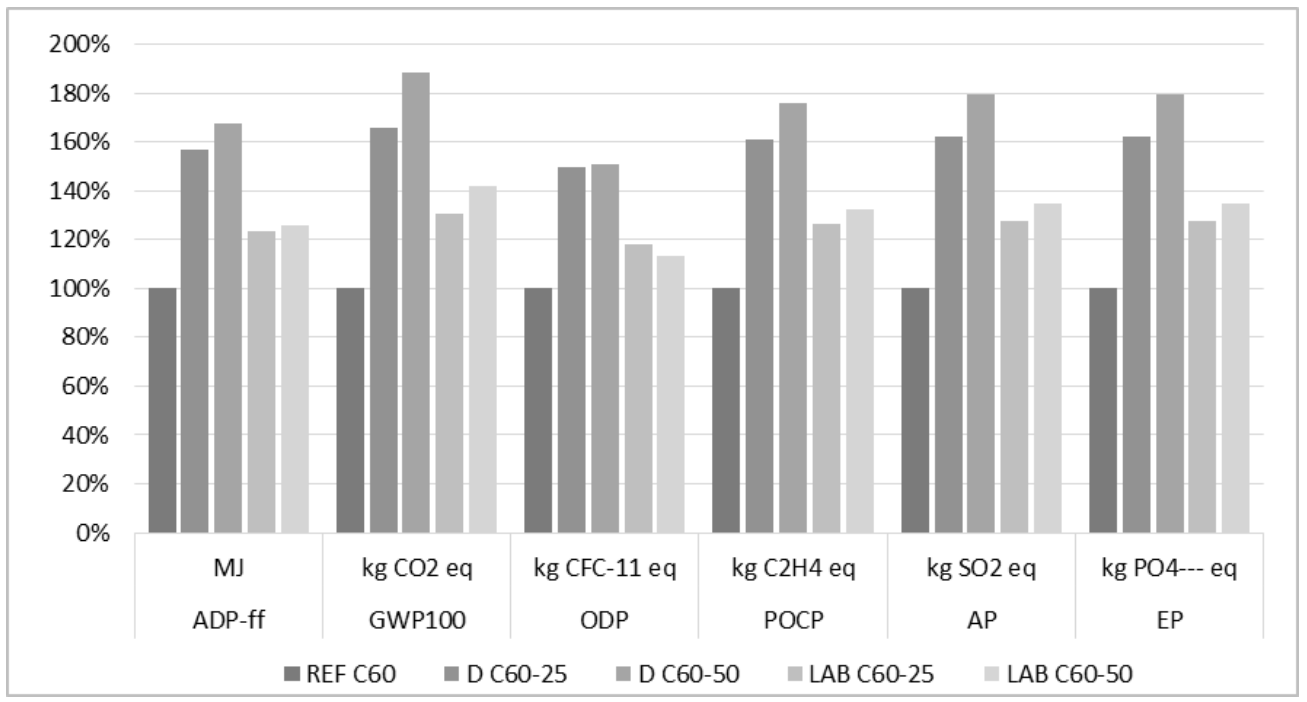

Figura 5: Potencial de impactos dos concretos C60 com 1MPa de resistência e 1 ano de vida útil, normalizados pela mistura de referência

Para concretos de classe de resistência de $30 \mathrm{MPa}$, a utilização da areia $\mathrm{D}$ ocasionou um incremento nos potenciais de impacto de até $51 \%$, enquanto a areia LAB, aumentou em até $7 \%$ os impactos quando utilizada em frações de $25 \%$, e em $12 \%$ quando utilizada em fração de $50 \%$.

Nenhuma das misturas estudadas apresentou redução do potencial de impactos em todas as categorias, quando comparada ao concreto de referência. A categoria ADP-ff apresentou uma redução de cerca de 5\% dos impactos com a utilização da areia LAB. Já a categoria ODP apresentou uma redução de cerca de $6 \%$ quando utilizadas frações de $25 \%$ de agregado reciclado, e $25 \%$ quando utilizado $50 \%$ de areia LAB.

Para ambas as classes de resistência, a mistura com $50 \%$ de areia D foi a apresentou maior potencial de impacto em todas as categorias analisadas, superando em $50 \%$ a mistura de referência para o potencial de mudanças climáticas a classe C30 e em $89 \%$ para a classe C60.

A mistura com $50 \%$ de areia LAB foi a que apresentou menores potenciais de impacto na classe C30 em comparação à mistura de referência, reduzindo em cerca de $20 \%$ o potencial de depleção da camada de ozônio e $10 \%$ a depleção de 
recursos bióticos. No entanto, no que se refere à categoria de mudanças climáticas possui um potencial de impacto cerca de $10 \%$ superior ao concreto convencional.

Para os concretos de classe $\mathrm{C} 60$, a mistura que apresentou menor potencial de impacto foi a composta de $25 \%$ de areia LAB, com exceção à categoria de depleção da camada de ozônio, na qual a mistura com 50\% de areia LAB apresentou um potencial de impacto inferior.

Para as categorias POCP, AP e EP, a utilização de areia LAB resultou num incremento dos potenciais de impacto de cerca de 3\%. Quando utilizado a areia D esse valor subiu para $8 \%$ quando utilizada frações em $25 \%$, e $38 \%$ quando utilizada fração de $50 \%$ de agregado reciclado.

As categorias POCP, AP e EP tiveram um incremento do potencial de impacto nos concretos de alta resistência de cerca de $30 \%$ quando utilizada a areia LAB, incremento de $62 \%$ com a utilização de $25 \%$ de areia D, e incremento de $78 \%$ com a utilização de $50 \%$ de areia D.

\section{CONCLUSÕES}

A análise individual do processo de produção de $1 \mathrm{~m}^{3}$ de concreto indica uma redução no potencial de impacto de todas as categorias, em função dos impactos evitados com a utilização de agregados provenientes de RCD. Estudos anteriores como o de Estanqueiro (2012) já demonstravam que o processo produtivo de agregados reciclados é ambientalmente mais favorável do que a utilização de agregados naturais.

No entanto, ao se estabelecer os parâmetros mínimos de resistência de 1 MPa e durabilidade 1 ano, percebe-se que todas as misturas apresentaram quedas significativas no desempenho ambiental, sendo mais evidente nas misturas com classe de resistência C60.

Para o potencial de mudanças climáticas, em específico, percebe-se que, mesmo quando considerado apenas a produção de $1 \mathrm{~m}^{3}$ de concreto, não há reduções significativas nas emissões de $\mathrm{CO}_{2}$, o que pode ser explicado pelo fato de a proporção de cimento ter tido pequenas variações quando da substituição da areia natural pela areia reciclada, e este concentrar a maior parte das emissões de $\mathrm{CO}_{2}$ durante o seu processo produtivo.

Por outro lado, a utilização de areia reciclada apresentou uma tendência de redução de potencial de impacto da categoria de depleção da camada de ozônio. Segundo Passuello et al (2019) tal influência está relacionada à emissão de compostos halogenados ao ar durante a produção do agregado natural.

Conforme apresentado na Tabela 2, a utilização de ARC não afetou de forma significativa a resistência mecânica das misturas, no entanto implicou em uma redução considerável do tempo de vida útil das estruturas, o que está relacionado diretamente ao teor e à qualidade da argamassa aderida aos grãos de areia reciclada.

A porosidade da pasta aderida aos grãos de areia reciclada fez com que os concretos com ARC apresentassem um ambiente menos resistente ao ataque de íons cloreto. O fato do potencial de impacto das misturas com areia D serem superiores aos concretos moldados com areia LAB indica que o concreto de origem da areia D possui uma qualidade inferior ao concreto que deu origem à areia LAB.

Dessa forma, conclui-se que a utilização dos agregados miúdos reciclados em substituição aos agregados naturais deve levar em consideração a caracterização do concreto de origem. Os resultados apresentados indicam que a utilização até $25 \%$ de areia LAB é viável, no entanto está limitada a concretos com classes de resistência convencionais. A utilização do material em concretos de alta resistência não é ambientalmente recomendada em ambientes de névoa salina.

\section{REFERÊNCIAS}

Associação Brasileira de Empresas de Limpeza Pública e Resíduos Especiais - ABRELPE. Panorama dos resíduos sólidos no Brasil-2017., São Paulo, Brasil, 2017. Disponível em: <http://abrelpe.org.br/panorama/.> Acesso em: 15 de set. 2019.

ANDRADE, G., P. Dosagem Científica de Concretos Contendo Agregado Miúdo de Resíduo De Concreto. Dissertação de M.Sc., COPPE/UFRJ, Rio de Janeiro, RJ, Brasil, 2018. 
ASSOCIAÇÃO BRASILEIRA DE NORMAS TÉCNICAS. NBR 14.040: Gestão ambiental - Avaliação do ciclo de vida - Princípios e estrutura. Rio de Janeiro, 2009.

ASSOCIAÇÃO BRASILEIRA DE NORMAS TÉCNICAS. NBR 14.044: Gestão ambiental - Avaliação do ciclo de vida - Requisitos e orientações. Rio de Janeiro, 2009.

AMERICAN SOCIETY FOR TESTING AND MATERIALS. ASTM C1.202: Standard Test Method for Electrical Indication of Concrete's Ability to Resist Chloride Ion Penetration., West Conshohocken, PA, 2012.

COELHO, A, DE BRITO, J. Environmental analysis of a construction and demolition waste recycling plant in Portugal - Part I: Energy consumption and $\mathrm{CO}_{2}$ emissions. Waste Management, v.33, p. 1258-1267, 2013.

Departamento Nacional de Produção Mineral. DNPM. Economia Mineral do Brasil. Brasília, Brasil, 2009. Disponível em: <http://www.anm.gov.br/dnpm/publicacoes/serie-estatisticas-e-economia-mineral/outras-publicacoes-1/0-sumarioapresentacao-e-introducao. $>$. Acesso em: 10 out. 2019.

European Federation of Concrete Admixtures Assosiations - EFCA. Environmental Product Declaration - Concrete admixtures - Plasticisers and Superplasticisers, 2015. Disponível em: < http://www.efca.info/publications.html>. Acesso em: 10 out. 2019.

ESTANQUEIRO, B. A. M. Análise de ciclo de vida da utilização de agregados reciclados no fabrico de betão. Dissertação de M.Sc., Universidade de Lisboa, Portugal, 2012.

GULIKERS, J. Predicition models for chloride ingress and corrossion initatation in concrete strutures. Goteborg: Chalmers University of Technology, 2001

MEDEIROS, M. H. F. Contribuição ao estudo da durabilidade de concretos com proteção superficial frente à ação de íons cloretos. Tese de D.Sc., USP, São Paulo, Brasil, 2008.

MEDINA, E. E. F. Evaluación comparativa de concreto con agregado natural y concreto a partir de agregado reciclado de prefabricados de concreto, bajo in análisis de ciclo de vida. Maestria em Construcción, Universidad Nacional de Colombia, Bogotá, Colombia, 2018.

NEVILLE, A. M., BROOKS, J. J. Tecnologia do concreto. 2. ed. Porto Alegre, Bookman, 2013.

PASSUELLO, A.C.; VENQUIARUTO, S.; ABREU1, A.G., et al. Valorização de resíduos de ágata em argamassas e concretos: avaliação do ciclo de vida. Matéria, vol.24, n.2. ISSN 1517-7076, 2019.

DE PAULA, R. R. Avaliação do ciclo de vida (ACV) de argamassas e concretos produzidos com resíduos de construção e demolição (RCD). Dissertação de M.Sc., COPPE/UFRJ, Rio de Janeiro, RJ, Brasil, 2016

RANGEL, C. S. Desempenho Mecânico, Estrutural e Durabilidade de Concretos de Resistência Normal e Alta Resistência Produzidos com Agregados Reciclados de Diferentes Origens. Tese de D.Sc., COPPE/UFRJ, Rio de Janeiro, RJ, Brasil, 2019.

SILVA, L. C. Avaliação de ciclo de vida de concretos com substituição parcial de cimento por cinzas do bagaço de cana-de-açúcar e da casca de arroz. Dissertação de M.Sc., COPPE/UFRJ, Rio de Janeiro, RJ, Brasil, 2015.

TEIXEIRA, L. P., DE CARVALHO, F. M. A. A construção civil como instrumento do desenvolvimento da economia brasileira, Revista Paranaense de Desenvolvimento, n. 109 (Jul/Dez), pp. 09-26, 2005.

VAN DEN HEEDE, P., DE BELIE, N. Durability related functional units for Life Cycle Assessment of high-volume fly ash concrete, Second International Conference on Sustainable Construction Materials and Technologies Porceedings, 583-594, Ancona, Itália, 2010. 